\title{
An end to the search for new drugs?
}

\author{
M. Weatherall*
}

THE discovery of new drugs is taking longer and becoming less productive ${ }^{1-3}$. In the United Kingdom the average time between first publication (itself usually years rather than months after studies begin) and marketing increased from 6 years in 1965 to 10 years in $1978^{4}$. In the United States the average time between filing an "Investigational New Drug", (IND) - in effect advising the authorities of an impending trial in man - and approval by the authorities of a drug for general use increased from about $3 \frac{1}{2}$ years in 1967 to 9 years in $1976^{5}$. One British pharmaceutical company has found ${ }^{6}$ that between 1972 and 1978, the number of animals used in safety testing increased from 600 to 1,200 or more and that the number of man-days spent by trained staff on a single nonrodent study increased from 275 to 480 despite improved working methods which saved 85 man-days. Unpublished figures from the Wellcome Foundation show that the cost of studies necessary before clinical trial of a drug intended for long-term use in man rose between 1965 and 1979 by a factor of 3.2 for toxicology and 5.2 for pharmacokinetics, even after correction for inflation.

The money for this work has to be found somewhere. The more that is spent on bringing one drug into general use, the fewer the total number of drugs that can be studied and the more necessary it becomes to concentrate on common diseases where the prospects of a financial return are greatest. Drugs for rare diseases sometimes called "orphan" drugs - such as triethylene tetramine for Wilson's disease $^{7}$ or L-5-hydroxytryptophan for myoclonus ${ }^{8}$, are not commercially viable and so must be prepared in a physician's laboratory and encapsulated in a hospital pharmacy ${ }^{7}$ if patients are not to be allowed to die.

It seems probable that financial pressures have already reduced the total research in the United Kingdom directed at finding new drugs. Cavalla ${ }^{9}$ lists nine companies which have closed their research and development groups, with redundancies or reorganization.

It can, of course, be argued that drugs are useless if not positively dangerous, and that the resources used in drug research would be much better spent on measures of more general benefit to the health of the community. There is a need to balance drug development against spending on

*Dr Miles Weatherall was Director of Establishment, Wellcome Research Laboratories, Beckenham, Kent until, 1979. Presen address: Willows, Church Lane, Charlbury, Oxfordshire OX? 3PX, UK community health, preventive medicine and relevant education. But as the funds come from different sources, striking a balance is necessarily difficult. Making drug development a government responsibility is not, however, an answer. A government concerned to live within its income from taxation would face the same problems as industry, and would perhaps be even more reluctant to undertake the risks of financial loss associated with speculative research, the problems of making orphan drugs available for uncommon but killing diseases and so on. Ultimately, health can be achieved and maintained only by work. The limit of health care is the amount of work which is put into it, and unless the work is unpaid, the limit is economic.

Meanwhile, until the balancing act is achieved and the public desire for medication $^{10}$ abates, drugs will continue to be a major element in therapeutics and better drugs will be sought. No drug is without its hazards. The one prediction that can con- evidence about the effects of drugs used by specialists in closely supervised patients. The effects may differ greatly when a drug is released for widespread and unregulated use. Information about the overall prescribing of drugs is of little help in assessing benefit, while the proportion of prescribed drugs actually consumed by patients is usually not known. The reporting of adverse reactions is patchy and biassed, and the fashion for expressing alarm about iatrogenic disease needs to be tempered by a careful appraisal of how the sufferers would have fared without the treatment.

In particular instances, thorough studies allow an assessment of risk. Thus immunosuppressive treatment, with azathioprine, chlorambucil or cyclophosphamide, is used to prevent rejection of transplanted kidneys. These treatments carry a $1.3 \%$ risk of tumour induction and $0.4 \%$ risk of mortality within the period of observation $^{13}$. But this risk has been estimated only after ten years of study. It could not

Public demand for totally safe drugs has led to excessive, costly and misleading toxicity testing. Such testing drains the resources which have been available for discovering much needed new drugs. Better public understanding of the limitations of toxicity testing and the hazards of medication is sorely needed in order to improve the prospects for diseases still needing effective treatments.

fidently be made about any new drug is that it will have unwanted effects, and dangers if misused"'. Moreover, it is usually difficult to assess what contribution drugs have made to the reduction of ill health and prolongation of life, when sanitation and nutrition have improved at the same time. Yet in a variety of circumstances, drugs are unequivocally saving individual lives ${ }^{12}$, as with the use of antibiotics in a wide range of acute infectious diseases, and of vaccines in the elimination of smallpox throughout the world and in the minimization of diphtheria and poliomyelitis in many countries. Replacement therapy prolongs life unequivocally: no one could seriously maintain that all diabetics could remain healthy without insulin. There is no doubt that some drugs are vitally necessary.

There is also no doubt that over a wide range of drugs, the evaluation of therapeutic benefit is extremely difficult. Difficulties arise when prolongation of life and easement of disability are the main expectations. Mortality statistics in more developed countries are good, but morbidity statistics are variable and, except for notifiable diseases, hard to come by. Clinical trials seldom extend over more than a year or so, and by their nature give have been estimated when renal transplantation began. Had it been possible to know it, and had it been added to the operative risks and other hazards, would it have been a reason for not embarking on the procedure and would most of the people now living with transplanted kidneys have been allowed to succumb to their disease?

Drugs are tools which function by modifying the processes of life, and they cannot be labelled good or bad without considerable knowledge of the circumstances in which they are actually used. For many diseases, the drugs available now are clearly inadequate to restore health or even minimize discomfort and disability. Allergy, arthritis, cancer, cardiovascular disease, congenital abnormalities, psychiatric, neurological and a variety of tropical diseases all await effective treatments. There is a rapid growth in knowledge about the biochemical disorders and genetic background of many of these conditions, and either from such knowledge or by more empirical methods, new drugs continue to be found. But there is a drug lag in countries which have the most sophisticated regulatory arrangements ${ }^{14}$, and a virtual halt to the discovery of new drugs for poorer and less healthy nations ${ }^{15}$. 
One reason for the decline in innovation may be the difficulty of devising suitable laboratory experiments for identifying drugs for the unconquered diseases. When a disease is due to a known infecting organism, compounds can be selected according to knowledge of the biochemistry of the organism, or empirically. Such compounds can be tested against the organism in vitro and in vivo, and the most effective selected for further study. The search may be long, but the route is clear. It has led to the whole range of chemotherapeutic drugs and antibiotics which have outstanding powers of saving human and animal lives. But this field is largely worked out, except for the tropical diseases. It will grow again in importance, as more drug-resistant organisms evolve. The resources for such discoveries are still an important part of the infrastructure of public health.

\section{Drug searches}

For diseases not known to be due to an infecting organism, some other clue is necessary to start the search for useful new drugs. When a particular substance is shown to be lacking, its replacement is indicated, as with L-dopa for Parkinson's disease $^{16}$ and, earlier, in the various endocrine gland failures. New local hormones or mediators continue to be discovered, but it remains to be seen how extensive the practical therapeutic consequences will be of the great body of recent work on prostaglandins, leukotrienes and neuropeptides. There are advances to be made in neuropharmacology as the relationships between disorders of synaptic transmission and mental disease become understood. At present the field is confused and confusing, and hampered by the lack of reliable animal models for essentially human disorders. So, too, diseases involving some ill-defined immunological disorder rheumatoid arthritis ${ }^{17,18}$, allergies of all kinds, perhaps multiple sclerosis ${ }^{19}$ - must either await biochemical understanding or rely on animal models justified in the main because they give positive results with agents already known to be effective in the human disease. This is a route to me-too drugs (not necessarily worthless) and to much waste of resources on false positives, but it is not likely to lead to great innovations in therapy.

The other major strategy for discovering new drugs is to pursue the detail of a physiological or biochemical system and to exploit its practical application. This is the natural course of academic scientists, and has led to such important agents as insulin and dimercaprol. In the past thirty years, however, the practical application by academic scientists of their discoveries has declined $^{20}$, partly because the resources now needed for development are completely beyond the range of university facilities and partly because increasing specialization within universities has reduced the cross-links between approp- riate specialists, especially organic chemists with pharmacologists, and pharmacologists with clinicians ${ }^{21}$. The fundamental approach has been pursued more successfully in industry, notably in Hitchings' work ${ }^{22}$ on purine and pyrimidine metabolism and inhibitory analogues, which led to drugs as diverse as the antimalarial pyrimethamine, the antineoplastic agent 6-mercaptopurine, the immunosuppressant azathioprine, allopurinol for gout and the antibacterial trimethoprim. More broadly, all the developments of drugs associated wtih neuroeffector and synaptic transmission rest on the fundamental work initiated by Dale at Wellcome Research Laboratories, extended in countless other institutes and applied to practical ends by many pharmaceutical manufacturers.

A major development of this kind is necessarily a long haul and involves extensive investment of resources in a concept, the therapeutic merit of which can be judged only at the end of the road. This kind of investment requires circumstances of prosperity and reasonable security, and is hindered if the always limited resources for research are frittered away in unimaginative and invalid routines.

In a reasonable world, the increasing difficulties of discovery and the seriousness of the incurable diseases may be seen as good grounds for a more tolerant attitude to the hazards of therapy. Desperate ills need desperate remedies, but the wish for completely safe remedies has had and is having the gravest effects on drug discovery $^{23}$. The problem of finding valid laboratory models for the unsuspected toxic effects of drugs is just as difficult as the problem of devising methods for detecting therapeutic potential.

The major tragedies which have created public alarm and fear and which have led to the condemnation of drugs have arisen in special circumstances (pregnancy and thalidomide; consumption of amine-rich foods and monoamine oxidase inhibitors; Japanese life and clioquinol ${ }^{24}$ ) or have been due to unexplained sensitivity in a minority of patients (triparanol 25 , practolol $^{26,27}$, clozapine ${ }^{28,29}$ ). Practolol, a $\beta$-blocking agent introduced for the control of cardiac arrhythmias and subsequently found valuable also in hypertension, is particularly notable for the thoroughness with which its toxicology was studied in animals, to the satisfaction of registration authorities. Nevertheless, adverse reactions, some serious, developed in a small proportion of patients who received the drug; the ill-effects included skin rashes, impairment of secretions and, most gravely, corneal damage sometimes leading to impairment or loss of vision (the "oculomucocutaneous syndrome").

None of the recognized laboratory procedures gave warning of the serious clinical syndrome nor, even with hindsight, has a procedure been discoverd which would have predictive value. Other "idio- syncrasies" are associated with particular genetic factors, as with reactions to suxamethonium $^{30}$, primaquine ${ }^{31}$, penicillamine $\mathrm{e}^{32}$, sodium aurothiomalate ${ }^{18}$ and hydralazine ${ }^{32}$. When much more is known about individual biochemical variation and its genetic control, it may be possible to predict that particular drugs will be hazardous to particular individuals. But the animal models of orthodox toxicity testing give no basis for such subtle predictions.

The unsatisfactoriness of predicting adverse effects in humans from animal experiments has been well known for a long time $^{33-36}$. Positive findings in animal experiments are also not always reliable evidence of harm to man. Usually, positive findings in experiments in animals are grounds for not giving a compound to human beings at all, but sometimes some toxic effect in animals is discovered after a drug is well established in clinical use. Furosemide, a well tolerated and valuable diuretic in man, causes severe liver necrosis in mice ${ }^{37}$ because of a metabolite which is not formed to a serious extent in humans ${ }^{38}$. The nucleoside 6-azauridine is tolerated for relatively long periods for cancer chemotherapy in man: in dogs, smaller doses than are acceptable in man produce potentially lethal bone marrow depression in 7-10 days $^{39}$. Intramuscular injection of iron sorbitol causes sarcomas at the site of injection in rats and rabbits ${ }^{40}$. The implication for human therapeutics appeared serious ${ }^{41}$; but the nonspecificity of the effect in laboratory rodents was recognized $^{42}$ and, nearly 20 years after the original observation in rats, only eight published cases could be found of tumours after intramuscular iron injection; their variety did not suggest a common origin from the injected material ${ }^{43}$.

\section{Species specificity}

Every species has its own metabolic pattern, and no two species are likely to metabolize a drug identically ${ }^{44}$. Small differences in the rate of conversion of drug to inactive, or to toxic, metabolite can have large effects on the concentration of active substance at the point of action. Most experiments to seek toxic effects in whole animals involve oral administration; differences in diet, gut physiology, rate of passage and liver enzymes raise serious questions about the relevance of findings in rats or mice to man. Compounds which are not absorbed in laboratory animals are not, with minor exceptions, ever tested in man. Nobody knows how many drugs, which would be useful in man, have been lost in this way. Similarly compounds toxic in laboratory animals at doses near the predicted therapeutic level do not receive trial in man, so it is never revealed whether they would actually have been harmful in man. Thus we lack the evidence of the false positive element in animal toxicology studies $^{39}$, so it is easy to give more weight to such studies than is justifiable.

The procedures ${ }^{45}$ which became 
established after thalidomide whereby large numbers of animals were fed large amounts of drug for a long time, have become ritual "routine tests of limited value and governed by regulations rather than by rational thought" 46 . Reports on the results are submitted to regulatory bodies in confidence and seldom published. The experiments are rarely repeated by independent workers: nobody is motivated to find the very considerable resources needed to do so.

Supplementary tests - for effects in pregnancy and on fertility, for carcinogenicity, for mutagenicity - grow in number but not in validity, and the search for quicker and cheaper tests, notably using mutagenicity in bacteria in vitro as evidence of carcinogenicity in vivo, has added to the obstacles, uncertainties and expense of developing drugs. As with the primary toxicity tests, positive findings are a bar to further progress, and to validating the test, so that the procedures acquire a possibly unmerited aura of respectability. The greater the number of tests, the greater the chance of a false positive and the loss of a useful drug.

There are good reasons for special caution in applying results of experiments in vitro to conditions of practical use, especially when massive concentrations are used. In mutagenicity tests, for example, considerable adjustment of experimental conditions appears to be necessary to obtain a positive result with a chosen compound. Ashby and Styles ${ }^{47}$ list 14 factors which can be varied in, and influence the outcome of, the Ames test, which is widely accepted as a standard basic procedure. By variation of any one or more of these factors, the sensitivity of the test can be altered, sometimes by as much as 400 -fold. For the innocent who wish only for a black or white answer, the outcome can be readily changed from positive to negative or vice versa.

\section{In vitro reliability}

In other words, there is a considerable scope for adjusting the test to give the required answer with any specified compound, and it is a great help in selecting test conditions to know what answer is wanted. Ames and Hooper ${ }^{48}$ observe that " using rat liver homogenate as a model for a rat's metabolism of foreign chemicals is a reasonable first approximation'. But, in vivo, compounds are metabolized and excreted, either unchanged or as metabolites. It is as important to mimic the mechanisms of inactivation as of activation if misleading results are to be avoided. The actual concentrations to which DNA is exposed in real life are quite unpredictable from concentrations produced in such experiments in vitro. The use of human instead of rat liver would add marginally to the predictive value of such bacterial tests for human mutagenesis. The addition of further enzyme systems might be better still, but would not overcome the problem of relating the tests to real life concentrations and duration of exposure.

Indeed, unless mutagenicity in vivo differs from all known pharmacological effects, it will be affected by the concentration of the agent to which the DNA is exposed and by the length of time and by the frequency of exposure, none of which can be properly assessed from data in bacteria in vitro. Even if mammalian DNA is damaged in the same way as the DNA of bacteria in a test situation, repair mechanisms are well known in mammals ${ }^{49}$, and may annul any damage so caused. The extent of their protective role has yet to be established. But no compound has been proved to be a mutagen in man and, 35 years after the massive radiation of the people of Hiroshima and Nagasaki, no deleterious heritable mutations have been recognized, so the protection afforded by repair mechanisms has had a substantial trial and appears to be pretty good.

Finally "the" correlation between mutagenicity (in bacterial tests) and carcinogenicity in humans is anything but simple. Many more carcinogens are known in rats than in humans and demonstration of carcinogenesis in rats sometimes depends on notably large and repeated doses of the substance under test $t^{50}$. The importance of a carcinogen, as of any other toxic or therapeutic agent, depends on the concentration and persistence of the substance at the site of action, or more roughly on the dose and duration of exposure. Disregard of quantitative considerations is the first step - and it can be a very long step indeed - towards nonsensical prediction and the abandonment of useful substances on ridiculous grounds ${ }^{50}$.

The problem remains of deciding what weight to attach to results of ominous but uncertain significance. The quicker and cheaper a test, the greater the number of substances on which suspicion may be cast. The list already includes the essential antimalarial drug chloroquine $\mathrm{e}^{51}$, and such more familiar substances as caffeine ${ }^{52}$, tap water $^{53}$ and oxygen ${ }^{54}$. Common sense prevents alarm about oxygen, which does, after all, damage the lungs and central nervous system of adults ${ }^{55}$ and cause blindness in premature infants ${ }^{56}$ at only five times the normally accepted concentration. Indentification of a hypothetical carcinogen or co-carcinogen among the solids dissolved in some samples of tap water is less certain to lead to a major advance in public health than to promote expensive but nugatory research, paid for by charity or the public purse.

Coffee drinkers are no more likely than smokers to be diverted from their habits. The epidemiological evidence of association between coffee drinking and carcinoma of the pancreas ${ }^{57}$ requires further investigation to establish whether one causes the other or whether both arise from an unidentified cause, but such an investigation will at least relate directly to a human problem. Will regulatory authorities become concerned with chloroquine regardless of its place in the control of malaria? The regulatory authorities mostly operate in the rich countries, which can afford them and which are relatively untroubled by malaria. If chloroquine were banned as a mutagen in any western country, would its further supply to less developed countries appear to be morally responsible? The difficulties of preventing "character assassination" of a drug are great, witness the problems of phenacetin $^{58}$, metronidazole $\mathrm{e}^{59-61}$ and Debendox ${ }^{62}$, but the resulting losses to human health may last for ever.

What really matters is what happens in everyday life. Recognition of the fallibility of laboratory studies has led to a welcome demand for surveillance of the effects of drugs in ordinary use $\mathrm{e}^{23}$. However, it is very difficult to measure the incidence of adverse drug reactions ${ }^{63,64}$, most of which are infrequent and occur in patients who are usually the recipients of several different drugs - and who may not necessarily consume the drugs prescribed for them. Naturally, a drug suspected of causing a reaction is withdrawn and many reactions subside. To give the suspected drug again so as to discover whether its toxic effect is reproducible, is hazardous and unethical, so evidence of individual cases is of very poor scientific quality.

\section{Simplify regulation}

Various schemes of surveillance have been proposed $^{65,66}$, by which it is hoped that quantity of evidence will overcome the weaknesses of separate observations. The accumulation of much data is essential, and the costs are substantial. If the price of drugs is not to rise, savings must be made elsewhere ${ }^{64}$. One obvious area is in preclinical evaluation and its administrative costs. The recent simplification in requirements in the United Kingdom for a clinical trial certificate ${ }^{67}$ are therefore welcome, though the financial savings will be modest. Studies of post-marketing surveillance are desirable, but if expensive schemes add to the economic barriers of discovering new drugs, they may yet achieve more social loss than benefit.

A basic difficulty lies in public opinion, and in the public belief that drugs can be, and ought to be, completely safe. Public conception both of the probability and of the severity of a risk is complex and not well understood. A single large-scale tragedy evokes much fear, as after an air crash or the sudden revelation that many deformed babies had been born after the use of thalidomide, whereas a continuous series of small tragedies, as in road accidents, is treated apathetically ${ }^{68,69}$. Most people understand that a surgical operation carries a finite risk, and face with more or less equanimity the remote possibility of death on the operating table or some other ill-fortune. But few appreciate a similar remote risk from consuming a drug, and the majority are correspondingly shocked 
when such an event occurs. The public view might be expressed in such words as "everything that could have been done to make a drug safe should have been done; even if tests are not very reliable, they had better be negative"'. A better understanding of the factors which create such views is needed if real safety and perceived safety can both be attained. Comparisons of the risk of taking the drug with the risk of omitting it from treatment are hard to make and harder still to present convincingly. And, ironically, it is not only wicked to do harm with a drug but often unethical to omit to administer it.

In this situation, the role of regulatory authorities is as unenviable as the position of the manufacturers. The regulatory authorities exist to protect the public. The losses incurred by delaying or banning new agents are neither obvious nor, as cold statistics, heart-rending. Occasionally, however, they have been measured. Delay in the introduction of the anticonvulsant drug sodium valproate on to the market in the United States has been estimated to have subjected American patients to approximately one million unnecessary seizures a year at a cost of approximately $\$ 200$ million a year ${ }^{70}$. Delay in the introduction of suitable anti-arrhythmic agents has been estimated to cost 10,000 deaths a year in the United States ${ }^{71}$.

Other substantial delays in introducing new drugs into the United States as compared with the United Kingdom have been carefully documented: 7 years for the first $\beta$-blocking agent for hypertension, 5 and $3 \frac{1}{2}$ years respectively for cromoglycate and inhaled beclomethasone for asthma, 5 years for cotrimoxazole for urinary infections ${ }^{70}$. It is difficult to estimate in every instance how many episodes of illness would have been prevented or treated more effectively if the drugs had been available. But presumably a sufficient quantity of evidence has accumulated in each case to justify the widespread use of the drugs. Why else did the Food and Drug Administration (FDA), in the end approve their use?

\section{Public pressures}

Unhappily, the balance sheet is not calculated solely on the best estimates of benefit and risk. Public opinion and political pressure weigh heavily against any suspicion of harm and are comparatively indifferent to benefits unless they are near miraculous. Triazure (azaribine) has been described by the director of the FDA's Bureau of Drugs as "a classic example of a highly effective drug which is useful to a small number of patients with a serious disease (psoriasis) but which also carries a serious risk of harm (thromo-embolism) in a fraction of those who take it" (J. R. Crout cited in ref. 72). It was released by FDA and later withdrawn, and its licensing became the subject of a congressional enquiry. Shubin's account ${ }^{72}$ of the proceedings raises serious questions about the exercise of medical judgement in a democratic society: clearly safety as a motive over-ruled any question of medical benefit.

Science does not flourish in the political arena, and the problem becomes philosophical: is it better to take risks in the hope of benefit, or to prohibit expected benefits because of an uncertain risk? Specific regulations are not as a rule unreasonable; it is the cumulation of requirements, their inconsistency between nations and their promotion of the mechanical check list as a substitute for reason and responsibility which achieves undoubted harm and uncertain good.

No manufacturer wishes to put unsafe drugs on the market, and it is natural to do what tests appear feasible to ensure safety, but the multiplication of tests of uncertain validity in no way makes them cumulatively any more reliable. It only increases the probability of rejecting useful substances on bogus grounds. It adds to the cost of developing new drugs, which is another way of saying that it diverts resources from discovery to supposed safety testing or, worse, to extensive experiments required to refute some suspicion raised on fashionable grounds but of dubious validity. And it delays the production of new remedies, during which time patients continue to suffer and die for lack of adequate therapy. One must have

\section{Nature 283, 609 (1980).}

2. Br. med. J. ii, $670(1980)$

3. Steward, F. \& Wibberley, G. Nature 284, 118 (1980).

4. Cromie, B. W. Br. med. J. i, 1618-1619 (1978).

5. Wardell, W. M., Dihaddo, J. \& Trimble, A. G. Clin. Pharmac. Ther. 28, 270-277 (1980).

6. Newbould, B. B. in Risk-Benefit Analysis in Drug Re search (ed. Cavalla, J. F.) 17-25 (MTP Press, Lancaster, 1981).

7. Walshe, J. M. Br. med. J. ii, 710-702, (1975).

8. Lasagna, L. Regulation 3, $27-32$ (1979)

9. Cavalla, J. F. Br. med. J. i, 1486 (1978).

10. Black, D. in Risk-Benefit Analysis in Drug Research (ed. Cavalla, J. F.) 179-184 (MTP Press, Lancaster, 1981).

11. Gross, F. Acta pharm. suecica 10, 401 (1973).

12. Beeson, P. Medicine, Battimore 59, 79-99 (1980).

13. Kinlen, L.J., Sheil, A.G.R., Pto, J. \& Doll, R. Br. med. J. ii, 1461-1466 (1979)

4. Wardell, W. M. Clin. Pharmac. Ther. 15, 73-96 (1974),

15. de Maar, E. W. J. Trans. R. Soc. trop. Med. Hyg. 73, 147-149 (1979).

16. Hornykiewiez, O. Br. med. Bull. 29, 172-178 (1973).

17. Stastny, P. J. clin. Invest. 57, 1148-1157 (1976).

18. Panayi, G.S., Wooley, P. \& Batchelor, J.R. Br. med. J. ii, 1326-1328 (1979)

19. Batchelor, J. R., Compston, A. \& McDonald, W. I. Br. med. Bull. 34, 279-284 (1978).

20. Dunlop, D. J. R. Soc. Med. 73, $405-407$ (1980).

21. Goldberg, L. Perspectives Biol. Med. 21, 167-195 (1979).

22. Hitchings, G. H. Cancer Res. 29, $1895-1903$ (1969).

23. Eur. J. clin. Pharmac. 11, 233-238 (1978)

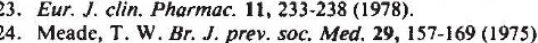

24. Meade, T. W. Br. J. prev. soc. Med. 29, 157-169 (1975).
25. Kirby, T. J. Trans. Am. Ophth. Soc. 65, 494-543 (1967).

25. Kirby, T. J. Trans. Am. Ophth. Soc. 65,
26. Wright, P. Br. med. J. i, 595-598 (1975).

27. Levy, M. \& David, D. Int. J. clin. Pharmac. 16, $479-481$ (1978)

28. Amsier, H. A., Teerenhovi, L., Barth, E., Harjula, K. \& Vuopio, P. Acta psychiatr. scand. 56, 241-248 (1977).

29. Anderman, B. \& Griffith, R. W. Eur, J. clin. Pharmac. 11, 199-201 (1977).

30. Kalow, W. Anaesthetist 15, 13-18 (1966).

11. Fraser, 1. M. \& Vesell, E. S. Ann. N.Y. Acad. Sci. 151, $777-794$ ((1968)

32. Batchelor, J. R. et al. Lancet i, 1107-1109 (1980).

33. Litchfield, J. T. J. Am. med. Ass. 177, 104-108 (1961).

34. Barnes, J. M. Proc. Eur. Soc. Study Drug Toxic. ii, 57.64 (1963).

35. Modell, W. in Drug Responses in Man (eds Wolstenholme, G. \& Porter, R.) 247-249 (Chuschill, London, 1967). 6. Fletcher, A. P. J. R. Soc. Med. 71, 693-696 (1978).

37. Mitchell, J. R., Potter, W. Z., Hinson, J. A. \& Jollow, D. J. Nature 251, 508-510 (1974)

38. Mitchell, J. R., Nelson, W. L., Potter, W. Z., Sasame, sympathy for the industry and regulatory authorities in attempting the impossible tasks of giving complete protection against drug injuries, satisfying the public and defusing those who would make political or financial benefit by exploiting such hazards. But there is no excuse for any parties promoting scientifically worthless or dubious procedures.

Resources are limited, and the diversion of resources in pursuit of safety inevitably reduces the resources available for more constructive purposes. Primum non nocere is a good doctrine for medical students to assimilate, but it is going beyond common sense to refrain from using a substance which may save a hundred lives for every one person whom it harms. It is more than ten years since the words ${ }^{73}$ were published "... the public and its administative watchdogs have the choice between some risks or no new drugs at all. No problems are avoided by the multiplication of unvalidated tests". But the habit persists of over-reacting to alarming information, of seeking safety without counting the cost of approaching it, of failing to preserve a balanced and scientifically acceptable appraisal of evidence of risk and of benefit. How long will it take for the experts to gain courage and for the unattractive message to be presented to and understood by the public at large?

H. A. \& Jollow, D. J. J. Pharmac. exp. Ther. 199 41-52 (1976)

39. Smith, C. G., Poutsiaka, J. W. \& Schreiber, E. C. J. int. med. Res. i, 489-503 (1973).

40. Richmond, H. G. Br. med. J. i, 947 (1959).

41. Haddow, A., Roe, F. J. C. \& Mitchley, B. C. V. Br. med. J. i, 1593-1594 (1964).

42. Grasso, P. \& Golberg, L. Food Cosmet. Tox. 4, 297-320 (1966).

43. Weinbren, K. Br. med. J. i, 683-685 (1978)

44. Gilette, R. J. in Drug Metabolism (eds Parke, D. V. \& Smith, R. L.) 147-186 (Taylor and Francis, London, 1976).

45. First Report of the Expert Committee on Drug Toxicity (Association of the British Pharmaceutical Industry, London, 1964).

46. Long Term Toxic Effects, a Study Group Report (The Royal Society, London, 1978).

47. Ashby, J. \& Styles, J. A. Nature 274, 20-21 (1978).

48. Ames, B. \& Hooper, K. Nature 274, 19-20 (1978).

49. Maher, V. M. \& McCormick, J. J. in Chemical Carcinogens and DNA Vol. 2 (ed. Grover, P. L.) 133-158 (CRC Press, Boca Raton, Florida, 1979).

50. Jukes, T. H. Clin. Tox. 14, 133-139 (1979)

51. Schupbach, M. E. Mutat. Res. 68, 41-49 (1979)

52. Nagao, M., Takahashi, Y., Yamanaka, H. \& Sugimara, T. Mutat. Res. 68, 101-106 (1979)

53. Gruener, N. \& Lockwood, M. P. Am. J. pub. Hith 70 , 276-278 (1980).

54. Kelly, M. \& Baden, J. M. Mutat. Res.77, 185-188 (1980)

55. Wolfe, W. G. A. Rev. Med. 26, 203-217 (1975).

56. Ashton, N. Am. J. Ophthal 62, 412-435 (1966).

57. MacMahon, B., Ven, S., Trichopoulos, D., Warren, K.\& Nardi, G. New Engl. J. Med. 304, 630-633 (1981).

58. Cuatrecasas, P. Science 203, 6-7 (1979).

59. Hartley-Asp, B. Lancet i, 981 (1979).

60. Hartley-Asp, B. Mutat. Res. 67, 193-196 (1979).

61. Hartley-Asp, B. Tox. Lett. 4, 15-19 (1979)

62. Pharm. J. 224, 493, 505 (1980) 226, 417 (1981)

62. Pharm. J. 224, 493, 505 (1980) 226, 417 (1981)

64. Vere, D. W. Proc. R. Soc. Med. 69, 105-107 (1976).

64. Vere, D. W. Proc. R. Soc. Med. 69, 105-107 (1976).
65. Dollery, C. T. \& Rawlins, M. D. Br. med. J. i, 96-97 Dollery, C. T. \& Rawlins, M. D. Br. med. J. i, 96-97
(1977).

66. Inman, W, H. W, Br. med. J. 282, 1131-1132, 1216-1217 (1981).

67. Griffin, J. P. \& Diggle, G. E. Br. J. clin. Pharmac. 12. 453-463 (1981)

68. Mole, R. H. Proc, R. Soc. Med. 69, 107-113 (1976).

69. Lee, T. R. Proc. R. Soc. A376, 5-16 (1981).

70. Wardell, W. M. Clin. Pharmac. Ther. 24, 499-524 (1978)

71. Wardell, W. M. Regulation 3, 25-33 (1979)

72. Shubin, S. Perspectives Biol. Med. 22, 185-204 (1979).

73. Hanley, T., Udall, V. \& Weatherall, M Br, med. Bull. 26 203-207 (1970) 